\title{
LA INQUISICIÓ I ELS REMENCES
}

\author{
Joan Ainaud $i$ de Lasarte
}

Durant el curs 1936-1937 no hi hagué classes regulars a la Universitat de Barcelona, però s'hi van mantenir algunes activitats científiques, entre elles les del Seminari d'Història de Catalunya, dirigit pel doctor Ferran Soldevila. Alli vaig coincidir amb el doctor Frederic Udina en les tasques d'edició de la tesi doctoral d'un mestre, company i amic, el doctor Jaume Vicens i Vives, dedicada a Ferran II i la Ciutat de Barcelona. El dotor Udina s'ocupava aleshores de la transcripció dels apèndixs documentals. Jo, molt més jove, treballava amb Dolors Teixidor en la preparació dels índexs alfabètics. Però aquesta tasca nostra, ben modesta en comparació amb la del doctor Udina, ens va permetre, també, de conèixer a fons la tesi del doctor Vicens i aprendre'n moltes coses, tant pel que fa al contingut com al mètode, i reflexionar detingudament sobre el valor del gran esforç del doctor Vicens, fins i tot en aquells aspectes en què jo discrepava, i discrepo, més essencialment. Un d'ells és, evidentment, en la valoració - per a mi totalment negativa- de l'aliança de Ferran II amb els elements més bruts de l'oligarquia barcelonina. Aquest no és, però, el tema del qual vull tractar ara, sinó sobretot de dos més força essencials i fins i tot, m'atreviria a dir, que d'una actualitat apassionant: la Inquisició i els remences. 
Això puc fer-ho, essencialment, gràcies a haver trobat, a l'Arxiu de la Catedral de Barcelona, el text d'unes extensíssimes instruccions, o capitols d'ambaixada preparats pels Canonges de Barcelona per als seus representants prop de Ferran II.

El text era totalment desconegut $\mathrm{i}$ ens presenta per primera vegada el punt de vista de l'Església -o d'un dels seus sectors més representatius - enfront del projecte reial d'introduir a $\mathrm{Ca}$ talunya la nova Inquisició amb un claríssim paper de policia política. Amb tot, per bé que una part de les al-legacions dels canonges em semblen raonables, penso que cal concedir un marge al dubte si el contraposem a la duríssima requisitòria contra el sindicalisme continguda en un altre apartat dels mateixos capitols.

Pel que fa a la Inquisició, el precedent més directe dels capitols esmentats, el trobarem en un procés incoat el mateix any $1484 \mathrm{i}$ del qual només teniem referències indirectes i posteriors. La magnífica tasca d'orientació de l'Arxiu Diocesà de l'Arquebisbat de Barcelona, la publicació del primer volum del catàleg (inventari) dels processos que conté i les facilitats obtingudes per al seu estudi m'han permès de conèixer el procés original núm. $1504^{\prime}$, en el qual el notari eclesiàstic Joan Busquets va registrar l'acció judicial empresa pel mestre Joan Comes, Inquisidor Diocesà de Barcelona, la Ciutat de Barcelona i els Diputats del Principat de Catalunya, actuant mancomunadament, contra els Inquisidors Juan Franco i Joan Caselles, que actuaven com a delegats de fray Tomás de Torquemada. El procés fou iniciat davant de la Cúria episcopal de Barcelona el 20 de juliol de 1484 amb la compareixença del mestre Joan Comes, qui va presentar una requisitòria contra els seus oponents, els delegats de Torquemada. En el mateix sentit i el mateix dia va manifestar-se el sindic de la Ciutat de Barcelona, Joan Mateu.

El 14 d'agost comparegué el Síndic dels Diputats de Catalunya, que presentà un escrit dels Diputats en què informa que davant de les pretensions de fray Juan Franco i dels mestre Joan Caselles fou votat i conclòs en el Consell Reial, davant de

I Jaume Comna I Vina. «Els processos dels segles XIV i XV ("Regesta")). Processos de I'Arxiu Diocesà de Barcelona, vol. I, Barcelona 1984. 
1'Infant Enric', lloctinent, que la pretensió dels nous inquisidors en «contra Constitucions de Catalunya, en lo qual Consell ha hagut gran nombre de doctors en quescun Dret a pràtichs en les Leys e libertats del dit Principat».

Com a conseqüència, la Generalitat es constituí també com a part en el procés, que després d'al-legacions molt copioses acabà el 27 d'agost amb una sentència, favorable al mestre Joan Comes, de la qual dono a continuació alguns extrets essencials:

"Circa horam terciam post meridiem» (...) «In quadam camera palacii episcopalis Domini Reverendi Barchinonensis Episcopi convenerunt ad consulendum egregios ac famosissimos jurisconsultos infrascriptos quos in dicta camera Episcopalis Palacii convocari et congregari... super altercacionem quae vertitur inter prefatos reverendos magistrosn.

In quo quidem Congregacionem fuerunt Jurisconsulti sequentes, per dictos dominos vicarios racione premissa convocati et congregati, videlicet:

Ferrarius Nicholaus de Gualbis, Canonicus et Archidiaconus Vallensis in Ecclessia Barcinonensi

Joahnes Vila

Bartholomeus Serra

Johanes Benedictus de Colle

Ludovicus Llull

Petrus Jacobus Boteller

Johanes Oliba

Johanes May

Hyeronimus Albanell

Andreas Solzina

Johanes Andree

Franciscus Jordá

Geraldus Gordiola

Gaspar Vilana

Jacobus Anthony

Johanes Raymundus Ferrarii

Sentencien «Quod Reverendi Domini Vicarii debent tenere et habere Reverendum Magistrum Johanes Comes pro inquisitore

${ }^{2}$ Codina, op. cit., pp. 303-304. El nom emprat per designar l'inquisidor $\mathrm{Ca}$ selles és ordinàriament el de Joan, per bé que en alguns indrets se l'anomeni Guillem. 
heretico pravitatis hiusmodi Civitatis et Diocesi Barchinone et cum eo ut cum Inquisitore heretice pravitatis in casibus de Jure statutis debere procedere et non cum alion.

El conflicte, no cal dir-ho, només havia fet que començar, i aquest fet justifica la primera part dels extensíssims capitols de l'ambaixada del Capitol als Reis, que per bé que la constituís un canonge (amb l'ajut de l'arquebisbe de Sàsser), era patrocinada per la Generalitat ${ }^{3}$.

Heus ací el text íntegre -i molt eloqüent- d'aquestes instruccions:

\section{L'afer de la Inquisiciót}

Memorial o instrucció per lo magnifich mossèn Johan Navarro, canonge de la sglésia de Barcelona, embaixador elegit per los reverends e magnifichs deputats del General de Cathalunya a les Magestats del Senyor Rey e Senyora Reyna sobre los fets de la Inquisició que's vol introduir specialment en la Ciutat de Barcelona e dit Principat, fet per lo Capitol e Sglésia de Barcelona. [e en cas que lo Reverendissim Senyor Archabisbe de Sàsser fos en Cort present, dites instrucciones sian a tots dos comunes e per els... se aja supplicar a dites Magestats.] .

E com lo dit Capitol de la Sglésia de Barcelona tinga la cara girada en tot lo que és servey de Nostre Senyor Déu e exaltació de la fe christiana, e haja gran desig de obeyr e servir a la Santedat de Nostro Senyor el Papa, a la Seu Apostòlica e a les dites Magestats. E per co delliberava elegir alguna digna persona de la dita Sglésia per donar avís a la dita Magestat del que comple al servici de Nostro Senyor Déu en la execució de la dita Inquisició, majorment en la dita ciutat, la qual, per gràcia de Nostro Senyor Déu, és neta de tots vicis de ydoletries e serimònies judayches, e de participi e conversació de jueus e altres infels, com en aquella no puixen habitar en alguna manera del món, ne·ls

${ }^{3}$ Berenguer de Sos.

${ }^{4}$ Aquest epigraf i els següents han estat afegits per mi. L'estil del document és molt descurat. Sembla haver estat escrit, de primera intenció, al dictat, la qual cosa dificulta una puntuació correcta. Lortografia és desigual, amb intercalació de mots llatins, castellans, i fins i tot italians, com forsa o força per forse (= potser), i freqüent amissió del que. 
comportarien tinguessen habitació en aquella, com fan en moltes altres ciutats, terres o regnes, per la qual occasió segueixen molts scàndels e s'abusa de la vera fe christiana.

Emperò, per tremetre tal persona fóra necessari al dit Capitol administrar algunes despeses, la que no.ls és stat possible per la gran inòpia és en la dita Sglésia, la qual és continuament veixada per molts talls e càrrechs continuament han a pagar per los censals són obligats per decimes e subssidis ja antigament posats e encara per anar hi tal persona com és la sua magnificència, qui complidament ultra lo càrrech a ell donat per los dits deputats suplirà a la honor $\mathrm{e}$ al que tocharà al descàrrech del dit Capítol,

E, primerament, plàcia al dit Magnifich mossèn Johan Navarro besar les mans a dites Magestats de Senyor Rey e Senyora Reyna, e humilment recomanarà lo dit Capitol e Sglésia a les lurs magestats, en la qual continuament se fa oració e pregàries per la vida e pròsper stat de lurs persones. E explicarà per part del dit Capitol e Sglésia a les dites Magestats que no obstant que per lur serenitat, com a zelans lo servey de Nostre Senyor Déu, la exaltació e defensió de la fe cathòlica com a devotissimos e christianissimos prínceps sia stat vist deure esser feta inquisició general contra los heretges e mals christians en la dita ciutat de Barcelona e Principat de Cathalunya, e per co sia stat tremés lo Reverend Mestre Johan Francho substituhit e subdelegat per lo Reverend prior de Prado, inquisidor general en totes les Spanyes per la Santedat de Nostre Senyor lo Papa assignat. Empero, considerant lo dit Capitol lo stament dels dits Ciutat e Principat, qui per grácia de Déu, com dessus és dit, són apartats per la mayor part de la comunicació de jueus e de infels e encara quant la humana fragilitat pot conéixer son lunyats de totes errós hereticals, e per esser lo Reverend Bisba de la ciutat de Barcelona e sos ministres ordinari e principal inquisidor, e encara tenint la dita ciutat special inquisidor per la Seu apostólica segons los privilegis per la dita Seu a la dita ciutat atorgats, los quals han vigilat e de continuo vellen que lo maligne sperit no pusche sembrar ab effecte en la díta Ciutat tals errós contra la fe cathòlicha, e si res hi senten pollular que deviàs a la veritat, ab tot sforç és obviat al que pogués portar irreverència o desonor a la Magestat divina. E perquè aquests respectes, e encar per les concitacions populars fetes en la dita Ciutat per causa de les fames que coren de les exequcions fetes en moltes parts de les Spanyes, tot lo stament de la dita Ciutat, vehent majorment lo dit Mestre Francho venir ab tant aparato e nombre de persones no acostumades de entrevenir en temps passat en lo of- 
fici de la Inquisició, lo qual offici simplament e sens scàndels per lo dit Reverend Bisba e sos ministres e per lo inquisidor specialment en la dita Ciutat e Bisbat de Barcelona en vigor dels privilegis a aquella atorgats, han acostumat ab tota puritat $\mathrm{e}$ integritat, com ocorra la necessitat e cars urgent, provehir que les animes deviants benignament, caritativa e humana sien reduhides ad ovile Christi, han delliberat suplicar humilment a les dites Magestats sia lur mercè e benignitat apartar la dita Ciutat, que per los infortunis de les turbacions passades és tant concassada, apobrida e atenuada que apenes poden spirar de totes molèsties, de tots scàndels, e de tota occasió que pogués portar dany als habitants e depopulació als poblats en aquella, com per experiencia huy se veja sols per aquesta demostració cessar de tot lo comerci en aquella, lo qual comerci cessant no pot restar dita ciutat no vingue a total ruyna e perdició. Lo que seria gran desservici de la lur Serenitat, que en lur temps majorment vingués dita Ciutat a perir, com sta aparellat.

E per co lo dit Capitol, essent attent e vigilant al augment e conservació de dita Ciutat, que redunden en servici de Déu e de lurs Alteses, quant més stretament poden, preguen al dit magnific mossèn Johan Navarro, embaixador, que de lur part explique a lurs Magestats lo que stesament ha hoyt e lo que presencialment ha vist de les comocions, terror, e spant que se són mesos en los pobles, senyaladament en aquells més populars, e de la turbació del comerci e del reposat viura de aquella Ciutat, com tal inquisició a present no pusque aportar sino dispopulació, grans inconvenients e dans irreparables a la dita Ciutat e a tot lo Principat.

Ne entén ne vol dir lo dit Capitol que per ço lo Reverend Bisba e inquisidor de la dita Ciutat hagen ommetre lo servici de nostro Senyor Déu e defensió de la Sancta fe cathòlica, ne hagen per co a cessar del exercici del offici de la Inquisició tota hora e quant los ocorrerá cas imminent e necessari. Emperò, sens scàndels ne commoció de la dita Ciutat, e sens denigrar la opinió e fama de bon christianisma que en dita Ciutat ça enrera és stada.

E jatsia lurs Alteses sien summament dignes de lahor de mirar e entendre en lo augment de la fe cahtòlica e de extirpar totes errós que fossen pollulades, emperò, per gràcia de Nostre Senyor Déu, essent la dita Ciutat neta de tals vicis com los pot esser feta relació per lo dit magnifich embaixador, hon alguna sinistre informació o encara vera fos pervenguda a les orelles de lurs Excellències per la... e per cessar tans inconvenients e scàndels... de virtuosíssimos Princeps, Reys i Senyors se pertany, e 
segons per los predecessors de loable e recordable memòria de lurs Alteses és stat en temps passat practicat, seran suplicades lurs Magestats per la... donen loch e hagen paciència que les novitats preparades e lo exercici del dit Mestre Francho, cessen. E tal exercici sia remès al dit reverend Bisba e al Inquisidor en la dita Ciutat e Bisbat assignat per la Seu Apostòlica segons forma dels privilegis atorgats, los quals les dites Serenitats han promès e jurat servar, e, majorment, que los dits Reverends Bisba e Inquisidor, obstants les leys pàtries e comunes no poden esser ne despullats ne perturbats ne molestats en lo exercici del dit offici, en lo qual no poria concorre lo dit mestre Francho ne altre, obstants los dits privilegis qui disposen un sol Inquisidor, lo qual no sia sotmès al Inquisidor General, sia deputat en la dita Ciutat e Bisbat, havent les qualitats en dit privilegi contengudes.

E per ço, en temps passat, trebellant alguns de alterar e subvertir la forma e pràctica del dit privilegi, fahent en acord cara e defensió e pràctica del dit privilegi, fahent en acord cara e defensió en favor de la dita Ciutat, lo gloriós Rey Don Johan, de eterna memòria, pare dels dits Senyors Reys, per jutges per apostòlica auctoritat sobre açò deputats per una e altres sentències fonch declarat e finat lo provehit segons forma dels dits privilegis deura usar del exercici de la Inquisició e les provisions en contrari obtingudes esser revocades, nulliusque esse efficacie seu momenti, e encara que, segons la fragilitat de humana natura importe, contra les dues sentències alguns volguessen insistir e per co fos stada feta comissió per la dita Seu Apostòlica a tres jutges specialment delegats, no s'és pogut obtenir per los insistins que dites sentències sien estades revocades, ans entre lo Inquisidor General de Aragó e de Cathalunya ab lo Inquisidor special dels dits Ciutat e Bisbat penja plet indecis devant los dits jutges, en prejudici de la qual littis pendencia no-s pot ne deu res innovar, disposant-ho tant les leys municipals com comunes, ans si res era attemptat en prejudici de la Ciutat privilegiada e del inquisidor en aquella deputat per viam attemptati, abans de alguna altre comissió se hauria a revocar.

$\mathrm{E}$ ab tot moltes altres rahons, e drets, sien allegats tant per part de la dita Ciutat quant del dit Inquisidor en aquella specialment assignat, par el dit Capitol aquestes aci exprimides sien sufficientíssimes per inclinar la mente de les règies celsituts en condecendee al de que seran per dit Embaixador suplicats, ço és, que benignament donen loch que lo Mestre Francho ne altre ultra los ordinaris e special deputat en la dita Ciutat se entremeten del exercici de la dita Inquisició.

E en cas lo Inquisidor special deputat en dita Ciutat e Bisbat 
proceesca en fer la inquisició e o ...... secundum forman juris comunis e de las leys de la pàtria, cessant tressores e altres officials no permesos a more (?) et legibus patrie.

Lo que lo dit Capítol, suplicant per lo servici de Déu e de lurs Magestats, bé e repòs de la cosa pública de la dita Ciutat, besant los les mans, humilment reputaran a singularíssima gracia e mercè e seran promptíssimos de continuo en lurs sacrificis e oracions fer memòria de la conservació de lurs reyals persones e del pròspero stat de aquelles.

E de aquestas... de la Inquisició comunicaran lo dit Mossèn Johan Navarro ab lo magnífich Mossèn Johan de Marimon, Embaxador a la dita Magestat per part de la Ciutat de Barcelona, e assò per mostrar unió.

\section{Les contribucions dels eclessiastics}

E per quant los dits reverendíssim senyor Archebisbe e Mossèn Johan Navarro són a plé informats de las diferèncias són stades e són, entre lo dit Capitol e ecclesiàstichs, de una part, e la dita Ciutat de la part altre, sobre las imposicions, drets, gravests fets a las personas ecclesiàstiques, ab la més cortesa manera que poran, scusant e justificant la Sglésia, la qual és tenguda defendre las libertats a ella per Nostre Senyor Déu atorgades, e ab la sua preciosa sang comprades, e ab jurament solemne per les lurs Magestats promeses defendre, explicaran a les ditas Magestats com aprés que la immortal memória del Senyor Rey Don Johan pare seu fonch entrat en dita Ciutat, e restituhida aquella e los habitants en lurs libertats, axí ecclesiàstichs com seculars, com acostumen los gloriosos Reys de la casa de Aragó, a la qual, per esser més dels altres defensors de la Sglésia, ha fet gràcia de ampliar lo nom, regnes e domini, e donar-los victòria de lurs inimichs, com vuy en die Nostre Senyor Déu, favorint e ejudant a las ditas magestats, fa e farà, intercedint las contínuas devocions, oracions e pregarias de las sglésias fundades en los regnes subjecte a la dita Magestat, en special en aquesta sua tant devota sglésia de Barcelona, molt graciosament e caritativa intercedí e fonch mediador la sglésia flixars en mudar l'orde e la forma de comprar las vitualles que los ecclesiastichs acostumen de comprar per que - $s$ deya la Ciutat diminuhiria de molts salaris e despeses, e succehiria en gran benefici de la Ciutat, e redrés de aquella.

Lo que fonch consentit per lo Capitol e ecclesiastichs de la Ciutat per servici de la dita Magestat, bé o redrés de la Ciutat, 
ab degudas salvatats e indemnitats de la Sglésia e libertats de aquella, e sens dan ne prejudici de las personas ecclesiastiques, e aixi aprés continuament la Sglésia ha consentit a totas las speriencias la Ciutat ha volgudas per lo redres de aquella. Seguintse per continuació de temps que la Ciutat que es quasi depopulade, e en la qual no.s fa exercici o molt poch de mercaderia e de altres grans negociacions se acostumaven fer en aquella, axi per mar com per terra, no pot inperar (?) ne conservar-se, ans quiscun die per experiencia se troba gran diminució en los drets en tant que no abasta a paguar los carrechs ordinaris en gran prejudici e dan dels curadors de aquella, los Consellers e Consell, per molt vagades e molt temps han conferit ab los del Capitol e ecclesiastichs se trobars alguna forma la Ciutat fos su. blevada, e fonch vist e conclos no havia altre ni més saludable remei que era luyr e quitar la part se poria dels cemsals fa la Ciutat, a fi que diminuhint aquella de carrech, poria diminuhir e lavar de las grans imposicions e drets fa la Ciutat, e seria cau. sa que axi com lo poble graviat de drets e ab pochs guanys se-n ha anar a cercar la vida en loch més franchs e liberts, tornaria e de nou vindria a poblar-se en la Ciutat. E per que no era posible fer tals luycions si de nou no-s trobave algun arbitre e expedient de hon exirien las quantitats qui servirien a fer tals luycions, fonch vist que per algun temps los de la ciutat diminuhisen los salaris reben, e-s cassassen alguns superfluus officis, se fessen arrendaments per las entrades dels portals e altres ahon stan tals ministres o molts de ells, prou insuficients e menys frats (?) e altres cosas, de que procehiren algunas quantitats se pogueren luyr quiscun any algunas sumas de censals. $\mathrm{E}$ en tal cas, lo Capitol e la Sglesia, per fer ditas luycions, per miga de las quals la Ciutat se spera sublevar, per servici de la sua Magestat, la qual ha significat per letras tenir gran voluntat en la sublavació de aquella e per conservació de la sua cosa pública, encara que la Sglésia no hi sia obligade, ans en la prestació dels censals de la Sglésia són obligats los bens e los censals dels laychs, emperó per caritat e pura amor e confederació lo Capitol e a la dita Ciutat e gloria seria lo redrés de aquella als tots, offeri a la dita Ciutat de subvenir-la e ejudar en fer dita luyció en certa forma, perque sortirs effete a cert temps de mil lliures quiscun any, que són traure la mes neta e pura sustancia, los eclesiàstichs tenen en la Ciutat per la gran destrucció e diminució an pres las lurs rendes, e prenen quiscun die per causa de la depopulació de la ciutat e destrucció de las casas e propietats en que la Sglésia pren las rendas. E encare és major offerta la Sglésia donar mil lliures que si la Ciutat ne donave vint mil. E poden dir e explicar los 
dits Archabisbe e Mossèn Johan Navarro a las ditas Magestats e suplicar aquellas sia de lur meercé e cleméncia girar la cara en aquest pobre stament ecclesiastich, lo qual, ultra los dita mals e molts altres innumerables, quiscun any ha a paguar talls, subsidis e càrechs, apenes las persones ecclesiàstiques poden sustentar lur miserable vida. E en aquesta Ciutat hon se viu ab gran despesa.

E la qual offerta, com no ignoren los dits archabisbe, e Mossèn Johan Navarro, no fonch acceptada, no perquè la quantitat no plàcia a la Ciutat, mas perque força als de la Ciutat e a tots no plau salaris se hagen a reduhir ne cassar officis ne arrendaments, de hon pot procehir moltat utilitat a la Ciutat.

Veritat és que, fahent tals arrendaments, se haurien a diminuhir molts officis, ab los quals lo Consell e govern de la Ciutat se pot regir per algú o alguns particulars. E per ço, dita Ciutat no acceptà tal offerta, ans ab molta presunció, algun o alguns dels qui aquell temps tenien lo regiment se asforçaren de imposar ley, e ordenar per indirectum sobre los ecclesiàstichs e astrènyer los en comprar les vitualles en hun loch per dits laychs deputat e assignat, contra voluntat e ab exprés dissentiment dels ecclesiàstichs. Lo que no és fet a moros ne a juheuts, contra tota libertat e privilegis e disposició de leys divinis e humanas. Lo que no fóra presumit fer ne executar per la dita Ciutat, si la sua Magestat se trobàs present o propinqua, ans com a virtuosissimo e christianíssimo Rey, de tal acte e tant a de servei de Nostre Senyor Déu e offensa de la divina Magestat, derogatòria a la sua Real auctoritat e juredictió, destructiva de la sua cosa pública, aparellade a grans scandels e avalots, concitats per alguns scandelosos, qui, defallints de rahó natural, ab crits e scàndels, crehent aterrir los ecclesiàstichs, aquells volien subpeditar, en tal forma que, defenent los ecclesiàstichs lurs privilegis, auctoritat e juredicció, essent ajustats en la plaça e sglésia de Sant Jacme los officials reals e ecclesiàstichs ab los Consellers e pròmens de la Ciutat e los ecclesiàstichs per disputar e determenar las diferèncias entre ells eren, fonch forçat lo Veguer de la sua Magestat dir algunas vaguades en presencia de tots que ell volguera aquellas diferèncias se lavassen en alguna manera, que ell veya e sentia si lo ajust se feya e la disputa, ell ne XIII Vagués no abastaran a provehir als scàndels eren aparellats. Fonch cosa tant dura hoyr de official real, e tant preheminent, hoyr tals paraules... alguna... de temor e terror, e al stament ecclesiàstich e en tal Ciutat subjecta a tant virtuós e christianíssimo Rey e Senyor qui vol sos vassalls de totas les personas del món puxen demanar justicia sens perill e temor de qualsevol persona per gran que sia, 
pur a la fi, ab moltas congoxas, creu-se consellade la Ciutat tals ordinació no podia ne devia fer per qualsevol privilegis tinguen de ordenar en la Ciutat sobre carnicers ne altres persones venents vitualles, ne pode tal privilegi usar sobre, ne en prejudici, dels ecclesiàstichs. E si per la Ciutat era dit era donade libertat als ecclesiàstichs comprar en hun lochs, e prohibir als altres, tal ordinatió feta sobre lo venedor, e prohibició, és vista esser feta sobre lo comprador. E així seria vista la Ciutat poria ordenar sobre lo ecclesiàstich comprador. Las quals ordinacions són lesivas, oppresivas, e derogatòrias la sglésia e stament ecclesiàstich e libertat ecclesiảsticha. E no.s pod scusar los que han fet tal ordinació, consentit, o ajudat e favorit no sien excomunicats maiori excomunicacione, e per ço foch feta altre ordinació ab consentiment dels ecclesiàstichs, qui continuament han consentit en totas ordinacions ha volgud la Ciutat esser benifici de aquella.

E si força serà pretès algú o alguns ecclesiàstichs fan fraus, per los quals la Ciutat reporta molts danys. És veritat que per algú o per alguns officials de la Ciutat, per poder-se vindicar auctoritat sobre los ecclesiàstichs, no poden trobar via sinó mesent los noms de rabiosos, criminant-los fan fraus, los quals, experimentats e provats, és vist e trobat malícia e passió, e no esser ver res de què sien stats criminats.

E per quant tots drets e imposicions són odiosos, e continuament molts treballen en fraudar-los, no afretura als ecclesiàstichs, qui de aquells són franchs. E lo que tots los ecclesiàstichs porien fraudar, és una misèria, que no-s deuria dir ne parlar. Mas $\mathrm{si} \cdot \mathrm{s}$ deya per quina, quals e quants fraus fets per laycs, e principals, e del govern, e per quantas vias la Ciutat ve a total ruhina, haurien bon callar.

Açò, los dits Archabisbe e mossen Johan Navarro, ab aquella sua acostumade prudència a discreció, diran lo que les paria esser necessari, no curant de mal dir ne criminar la Ciutat per no indignar la Magestat del Senyor Rey contra aquella. Ans us sia feta complir de justificació per part de la Sglésia e admesa per la dita Magestat... per part de la Ciutat la dita Magestat no era sinistrement informada contra los dits ecclesiàstichs. Se afforçarà impetrar letres de aquella per als Consellers a soles, e altres per als Consellers e Consell de la Ciutat, manant-los la Sglésia en cosa al món ne ordinacions per ells fetes ne fahedores no sia gravade ne prejudicade, ne usen de algunas sinó ab consentiment exprés dels dits ecclesiàstichs, attès las moltes justificacions e tolleràncias fetes per los Bisbe, Capitol e ecclesiàstichs per conservació hoc e augment de la Ciutat.

E perquè sortesque major effecte, li plàcia impetrar letres per 
al illustríssimo Senyor Infant no perete la Sglésia sia vaxade, ans stigue e visque en aquella plena, integre libertat acostumave star e viura en lo temps passat de pau e repòs.

Com per experiència Nostre Senyor Déu hage mostrat e mostre los Reys e Universitats observants la Sglésia Santa e las personas ecclesiàstiques, tals Reys esser acceptats a la sua divina Magestat, e donar-los glòria, exaltació e trihumpho dels inimichs, amor, fidelitat dels súbdits e vassalls. E per ço prestarà tot auxili e favor a la dita Sglésia e ecclesiàstiques personas, fahent los usar, viure e fruy en lurs integres libertats e juridiccions divinas e humanas, com tal sia la intenció de la sua Magestat.

\section{La sindicació dels capellans}

E com per nostres peccats la speriència nos hage mostrat quants de serveys a Nostre Senyor Déu, inhobedièncias a la Real Magestat, mals e dans als regnes e poblats en aquells ha aportats congregacions de pobles, specialment en aquesta Ciutat, en la qual, sots titol o color de sindicat, e podent se aquell ajustar, desiyós tota natura de poble de cosas novas, encare que sien scandeloses e ruyoses de tot bon stament, com és stat en aquesta Ciutat e Principat, que de hoyr anomenar tal nom de sindicat las orellas deurien aborrir e los ànimos tremolar, per grans que sien, que per occasió de tal nom, no sols aquesta Ciutat e Principat, mas tots los regnes de Aragó, han sostenguda e sostenen irreparable ruyna, e, encare si.s pot dir, tot lo món e stament, aixi de christians com infels, han pres extrema alteració.

E no content lo inimich de pau de tants mals, encare ha daxat alguna reliquia en aquesta Sglésia, suscitada per los sequassos populars dels qui la primera e major havien suscitada en impetrar del nostre prelat una forma semblant a la primera maligna de sindicat.

La qual, per no esser com devia lo dit prelat, aconsellat de mals ministres e ambiosos, ab preu apreciat atorguà, de què se han seguit grans desordes en aquesta sglésia, a deservey de Nostre Senyor Déu, e scàndels en aquella, diminució del cultu diví, inhobedièncias e consitacions. E, vist tals desordes se seguian per los ecclesiàstichs populars, per alguns discrets e dels principals del gran desorde e mal se podia seguir en la execució de tal sindicat, encare que hagen paguat la major part dels diners, han sobressegut en la execució del dit sindicat, lo qual fins así no ha hagut execució, amant més perdre los diners que destroyr aquesta tant insigne Sglésia. 
E lo Senyor Bisbe, publicament, ha confessat volguera tal cosa no fos atorguade, e li plaguera lo clero renunciàs a tal concessió. E, de fet, dit clero, o la major part, haguera renunciat, si no per algun dubte se és hagut, que pus haguessen renunciat, per los ministres del dit Senyor Bisbat (sic) foren executats per lo residuum, si algú $\mathrm{n} \cdot \mathrm{i}$ ha resta a paguar per dita concessió de sindicat a ells feta.

Per co, explicat tot lo demunt dit a la dita Magestat ab lo suplement e ornament de paraules e justificació per lo Capitol, suplicaran a la dita Magestat li plàcia manar e expedir letres per al illustríssimo Senyor Infant, al Capitol e al clero, declarant la sua voluntat e intenció esser no permetre tal sindicat hage execució.

E si força per inadvertència, vel alias, lletres algunas havia atorgades ne de qui avant atorgave, declare esser nulles, ne voler sortesquen effecte, ans vol sia per dit clero a ditas provisions de sindicat e de congregacions e altros privilegis al clero e comú e particular atorgats, qui sien en alteració alguna de la bona e loable prátique observade antigament en la Sglésia de Barcelona, sia renunciat.

Item, donaran la letra al magnifich mossen [Gaspar] d'Arinyo, Secretari del Senyor Rey, al qual recomanam en comú e particular aquest tant afectat Capitol e a ell per intercessor ab la Magestat del Senyor Rey haurà a interposar en lo demunt contengud, e altras cosas li paria sien necessaries per lo bé de aquesta Sglésia, la qual li és tant devota com la sua magnificència no ignora, e desige fer per la honor sua. La resta, perquè no és possible tant expremir com seria necessari, sia remés a la providència dels dits senyor Archabisbe e mossèn Johan Navarro. Los quals, per la lur virtut, pro suis viribus treballaran en obtenir tot lo que li parrà bé e honor de aquesta Sglésia e stament ecclesiàstich. E Nostre Senyor Déu lo dexa per ça mercè tornar salvo e content.

E per quant se diu lo Reverendíssimo Senyor Archabisbe de Sàcer vol anar a la Cort per servir e seguir a les sobredites reals Magestats, per esser tant digne e accepta a aquelles e la sua intervenció de la sua Reverendíssima sua Senyoria no pot sinó summament aprofitar, hoc encare és de creure, si algunas cosas eren difícils de obtenir, ab aquella la sua intervenció e industria seràn facils, plàcia al dit mossen Johan Navarro comunicar ab lo dit senyor Archabisbe... e tant dignissimo suposit de aquesta Sglésia, e a consell seu negociarr las fenas (?) a ell comeses per lo dit Capitol e Sglésia,

Huiusmodi instrucciones fuerunt expedite per me Dalmacium 
Ginebret notarium et scribam dicti Capituli de mandato honorabilium et circumspectorum virorum dominorum Ludovici dez Pla, Archidiachoni maioris, Ferrarii Nicholay de Gualbes, Archidiachoni Vallensis, Ludovici Sirvent, Bartholomei Travesset, Canonicorum Ecclesie Barchinonensi, in hiis per dictum Capitulum electorum.

VI septembris anno a Nativitate Domini MCCCCLXXXIIII fuerunt facte dicte instructiones.

En fulls solts, cosits ara en el mateix plec ${ }^{5}$, segueixen els esborranys de les credencials adreçades al rei, a la reina $i$ al secretari reial Gaspar de Arinyo, i la lletra d'encàrrec del Capítol al seu representant i concanonge (com diu ell), mossèn Joan Navarro.

He dividit el text dels capítols d'ambaixada en tres grups diferents, cadascun encapçalat per un epigraf, afegit per mi.

La primera part correspon a l'intent - no consumat fins al 1487- d'introduir a Catalunya la Inquisició reial ${ }^{6}$. Es tractava d'un problema molt greu i que considero totalment polític, molt lligat amb el concepte de la monarquia absoluta $\mathrm{i}$ al servei d'aquesta'. L'actitud del Capítol de Barcelona em sembla molt clara, des del punt de vista de la jerarquia eclesiàstica ${ }^{8}$. Però, a més, cal no oblidar que l'argument que els procediments terrorífics i estrepitosos blasmats pel Capítol no solament no cor-

${ }^{5}$ Arxiu de la Catedral de Barcelona, Secretaria, plec de Comissions. Dos bifolis grans i un de petit, a més d'uns fulls solts amb minutes de lletres.

${ }^{6}$ Aquesta Inquisició general rep habitualment l'adjectiu de castellana, en contraposició amb la tradicional en el país, però, tot i que una part dels seus promotors foren castellans, podria ser qualificada d'espanyola, si tenim en compte el títol d'inquisidor general en toles les Spanyes que els capitols d'am. baixada reconeixen a Torquemada, a més de la claríssima intenció política uniformista de tot l'afer.

${ }^{7}$ Uns anys després, un autor coetani tan addicte als Reis com el seu arxiver Pere Miquel Carbonell recull el contingut clarament politic de diversos interrogatoris de la Inquisició en la seva obra Liber descriptionis reconsiliationisque, purgationis et condemnationis hereticorum, publicada de 1864 a 1865 per Manum br Beinkui en els volums 27 i 28 de la CODOIN del Archivo General de la Corona de Aragón.

"Vegeu especialment Viciens, I, pp. 72 iss. 
responien en res amb un pretès «esperit general» del temps, com voldrien fer creure alguns errats apologetes, sinó que el mateix doctor Vicens ja va publicar un importantíssim document que demostra un esperit totalment contrari. Es tracta dels principis juridics basics - i en molts aspectes gosaria dir que exemplarsque els Consellers de Barcelona van formular com a contraproposta a la nova Inquisició .

Per completar l'estudi del tema caldria analitzar sobretot tres elements. Un d'ells, per ara introbable, és el dels processos episcopals barcelonins anteriors al $1484^{10}$. Un altre, els registres del Lloctinent, i dels Diputats, conservats a l'Arxiu de la Corona d'Aragó, i no utilitzats pel doctor Vicens, que ens donarien el punt de vista del Consell reial barceloni i de la Generalitat". Finalment, i des de l'òptica dels conversos, un document interessantísim, el llibre de comptes i de notes - en català- de Bartomeu Rodrigues, que el seu propietari devia amagar en una casa del carrer del Call, de Barcelona, on fou retrobat el mes d'abril de $1848^{12}$. Bartomeu Rodrigues havia pogut fugir de Barcelona i la seva estàtua fou cremada per la Inquisició, el 25 de gener de $1488^{13}$.

El segon punt fa referència a la problemàtica dels conflictes derivats de la contribució dels eclesiàstics a l'economia municipal, especialment, com a conseqüència del conflicte existent entre els antics privilegis d'exempció i la gravíssima situació general derivada de les turbacions, és a dir, de la guerra amb

9 Vicens, Apèndix, doc. 87, Barcelona, 13 de gener de 1486, pp. 166-171. Un comentari, en VICENS, I, pp. 391-394.

${ }^{10}$ L'inventari publicat per JAUME CodinA no conté cap al-lusió als processos anteriors al de 1484, tot i que per altres fons sabem que en van existir.

"Encara que també es trobin a l'Arxiu de la Corona d'Aragó, pertanyen a fons o sèries diferents dels registres reials.

${ }^{12}$ Diario de Barcelona 111, 20 abril 1848, pp. 1835-1836.

${ }^{13}$ Pere Miquel Carbonel., loc. cit., vol. 28, p. 13. El manuscrit es troba, actualment, a l'Arxiu de la Reial Acadèmia de Belles Arts de Sant Jordi, a Barcelona, juntament amb dos més trobats amb ell; I'un conté plecs de la traducció catalana dels Salms, en vitela; l'altre, en paper, un llibre de pregàries, en català, d'ús litúrgic jueu. Aquest darres, sense identificar-ne el propietari, fou publicat d'una manera molt provisional pel doctor Antoni Griera. 
Joan $\mathrm{II}^{14}$. El tema fou àmpliament recollit en la tesi del doctor Vicens, per bé que ara el document capitular completa els punts de vista dels Canonges ${ }^{15}$.

La part final del document és la més curta, però la que, al meu entendre, presenta més novetat. Tracta d'un tema del qual conec altres testimonis publicats i que il-lustra sobre la projecció - en analogia perfecta - de les incidències del conflicte remença en l'estructura social de l'Església.

La tàctica del rei de donar suport als remences contra les classes altes, no pas per afavorir els pobres sinó per consolidar la monarquia absoluta, troba una rèplica exacta en el dret de sindicació de les classes inferiors del clergat, afavorit pel bisbe de Barcelona per atuir els canonges. Els fortíssims atacs al sindicalisme penso que demostren clarament la realitat d'un conflicte social que va enfrontar els senyors i les classes inferiors. D'una banda, la noblesa, l'alta burgesia i l'alt clergat (pertanyent sovint a les mateixes famílies que els dos braços ja esmentats); d'una altra, els pagesos de remença i els capellans o beneficiats. Recordem que aquestes diferències serien aprofitades a l'Edat Mitjana per la monarquia i per la jerarquia episcopal, com ho seria durant la Revolució Francesa per trobar suport, en els seus inicis, en els rectors rossellonesos de les parròquies més modestes enfront del clergat catedralici o dels convents o monestirs més poderosos, en benefici de les noves autoritats revolucionàries.

Penso que no convé negar la realitat $\mathrm{i}$ fins $\mathrm{i}$ tot el fonament de certs conflictes, sense admetre, però, que la raó acompanyi necessàriament qui a la llarga se n'aprofita en detriment de les dues parts enfrontades.

Certament, per a mi, aquest afer de la sindicació del clergat obre perspectives ben interessants en molts ordres, tant pel que fa a la comprensió del mateix conflicte remença, com pel que

14 Vicens, vol. I, i Apèndix, en llocs diversos.

15 A més de la documentació aportada per Vicens, hi ha al-lusions en la semblança de l'Ardiaca Lluís Desplà, publicada per Agusti Duran i SANPERE, Barcelona i la seva Història, vol. I, Barcelona 1972, pp. 403-406. 
fa a un exemple particular d'una veritable lluita de classes. De fet, l'explicació més natural de l'evolució de les formes de l'organització eclesiàstica (no pas les de la vida espiritual pròpiament dita) és que la presenta en una evident simetria amb l'evolució de la societat civil, no sols per una normal interacció, sinó perquè en un i altres cas el subjecte és la societat humana. D'altra banda, penso que tot plegat té una possible relació amb la futura organització col-lectiva del clergat barceloni, si més no el catedralici, ja que imagino que aquest fou l'origen de la comunitat de preveres de Sant Sever, fundada el 10 de desembre de 1479 per impulsos del bisbe de Barcelona, Gonzalo Fernández Heredia ${ }^{16}$.

${ }^{16}$ PILAR Llopart, «Un monumento del barroco barcelonés: la Iglesia de San Severon, D'Art, 3-4, Barcelona 1977, p. 31, 